\title{
Inflammatory mediators in human acute pancreatitis: clinical and pathophysiological implications
}

\author{
J Mayer, B Rau, F Gansauge, H G Beger
}

\begin{abstract}
Background-The time course and relationship between circulating and local cytokine concentrations, pancreatic inflammation, and organ dysfunction in acute pancreatitis are largely unknown. Patients and methods-In a prospective clinical study, we measured the proinflammatory cytokines interleukin (IL)-

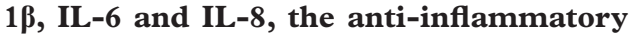
cytokine IL-10, interleukin $1 \beta$ receptor antagonist (IL-1RA), and the soluble IL-2 receptor (sIL-2R), and correlated our findings with organ and systemic complications in acute pancreatitis. In 51 patients with acute pancreatitis admitted within 72 hours after the onset of symptoms, these parameters were measured daily for seven days. In addition, 33 aspirates from ascites and the lesser sac were measured.

Results-Sixteen patients had mild acute pancreatitis (AP) and 35 severe AP (Atlanta classification); 18 patients developed systemic complications requiring treatment. All mediators were increased in AP. sIL-2R, IL-10, and IL-6 were significantly elevated in patients with distant organ failure. An imbalance in IL-1 $\beta$ / IL-1RA was found in severe AP and pulmonary failure. Peak serum sIL-2R predicted lethal outcome and IL-1RA was an early marker of severity. IL-6 was the best prognostic parameter for pulmonary failure.
\end{abstract}

Conclusion-Our results suggest that local mediator release, with a probable

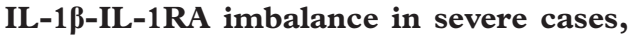
is followed by the systemic appearance of pro- and anti-inflammatory mediators. The pattern of local and systemic mediators in complicated AP suggests a role for systemic lymphocyte activation (triggered by local release of mediators) in distant organ complications in severe AP. (Gut 2000;47:546-552)

Keywords: pancreatitis; cytokines; lymphocyte activation; pancreatic necrosis; organ complications

Morbidity and mortality in acute pancreatitis (AP) is largely determined by distant organ failure in severe attacks. These systemic manifestations of a disease initially limited to the pancreas are thought to be mediated by a variety of pro- and anti-inflammatory mediators released from the pancreas and various other sources during the course of the disease. ${ }^{1}$ Studies on AP have demonstrated that these mediators are produced in a variety of tissues in a predictable sequence, initiated by local release of proinflammatory mediators such as interleukin (IL)-1 $\beta$, IL-6, and IL-8, which induce a systemic inflammatory response reflected by increased levels of soluble interleukin 2 receptor (sIL-2R), neopterin, or tumour necrosis factor $\alpha(\mathrm{TNF}-\alpha)$. This results in inflammatory infiltration of distant organs with multiorgan failure and death. ${ }^{1}$

The systemic inflammatory response is kept at bay by local and systemic release of antiinflammatory mediators such as interleukin $1 \beta$ receptor antagonist (IL-1RA) and IL-10 which were shown to reduce the severity of pancreatitis and pancreatitis associated organ failure. ${ }^{2-5}$ These observations demonstrate the potential of immunomodulation in preventing pancreatitis associated organ failure.

However, little is known of the relationship between the clinical course of AP in humans and the dynamics of the major cytokines, both locally and in the systemic circulation, in the presence or absence of distant organ complications. Therefore, we examined the relationship between local and systemic mediators in early $\mathrm{AP}$ in a prospective clinical trial.

\section{Patients and methods}

DEFINITIONS

Mild acute pancreatitis (MAP) was defined according to the Atlanta classification ${ }^{6}$ as confirmed acute pancreatitis without development of one or more major local or systemic complications caused by pancreatitis. Severe acute pancreatitis (SAP) was defined as AP associated with one or more major local or systemic complications caused by pancreatitis. Local complications include pancreatic necrosis, acute pancreatic fluid collection, pancreatic pseudocyst, or pancreatic abscess. Systemic complications include respiratory failure $\left(\mathrm{pO}_{2}\right.$ $<60 \mathrm{~mm} \mathrm{Hg}$ requiring oxygen therapy for longer than 24 hours or mechanical ventilation), cardiocirculatory failure (systolic blood pressure $<80 \mathrm{~mm} \mathrm{Hg}$ for more than 15 minutes), renal failure (serum creatinine

Abbreviations used in this paper: IL, interleukin; IL-1RA, interleukin $1 \beta$ receptor antagonist; sIL-2R, soluble interleukin 2 receptor; $\mathrm{AP}$, acute pancreatitis; MAP, mild AP; SAP, severe AP; TNF- $\alpha$, tumour necrosis factor $\alpha$; SIRS, systemic inflammatory response syndrome; CRP, C reactive protein; $L R$, likelihood ratio; ERCP, endoscopic retrograde cholangiopancreatography. 
Table 1 Complications of mild and severe acute pancreatitis (AP)

\begin{tabular}{|c|c|c|c|c|c|c|c|}
\hline & Necrosis & Pulmonary & Renal & Death & Sepsis & Shock & $\begin{array}{l}\text { Infected } \\
\text { necrosis }\end{array}$ \\
\hline Mild AP $(n=16)$ & 0 & 2 without ventilation & 1 without dialysis & - & - & - & - \\
\hline Severe AP $(n=35)$ & 34 & $\begin{array}{l}12 \text { without ventilation, } 18 \text { with } \\
\text { ventilation }\end{array}$ & $\begin{array}{l}8 \text { without dialysis } 6 \text { with } \\
\text { dialysis }\end{array}$ & 13 & 11 & $\begin{array}{l}7 \text { without catecholamines } \\
12 \text { with catecholamines }\end{array}$ & 9 \\
\hline
\end{tabular}

$>2 \mathrm{mg} \%$ in the absence of prior renal insufficiency), or the presence of gastrointestinal haemorrhage. Bacteria negative sepsis was defined as the systemic inflammatory response syndrome (SIRS) without positive blood culture according to the definitions of the ACCP/SCCM consensus conference committee. ${ }^{7}$ Sepsis was defined as blood culture positive SIRS.

PATIENTS

Patients with confirmed AP (clinical symptoms, amylase/lipase greater than three times the upper limit, and pancreatitis on ultrasound or computed tomography scan) who were admitted to our hospital as primary or secondary referrals within 72 hours after the onset of symptoms were prospectively entered into the study. The study was performed according to local ethics committee regulations and informed consent was obtained. Exclusion criteria were age $<18$ years, infection with hepatitis or human immunodeficiency virus, pregnancy, and refusal of consent. A total of 51 patients were included in the study; 16 suffered from mild AP (MAP) and 35 from severe AP (SAP) according to the Atlanta classification. ${ }^{6}$ Of the patients with MAP, seven were male and nine were female (median age 65 years (range 19-83)). The aetiology in MAP was biliary $(n=10)$, alcoholic $(n=4)$, post-endoscopic retrograde cholangiopancreatography (ERCP) $(n=1)$, and idiopathic $(n=1)$. Twenty four patients with SAP were male and 11 were female (median age 46 years (range 32-79)). The aetiology in SAP was alcoholic $(n=20)$, biliary $(n=11)$, post-ERCP $(n=3)$, and idiopathic $(n=1)$. Median Ranson scores were 3 for MAP and 6 for SAP, and median admission APACHE II scores were 7 for MAP and 14 for SAP. Both scores were significantly higher in SAP than in MAP $(p<0.05)$.

All patients with mild AP suffered from interstitial pancreatitis; two of these patients developed pulmonary insufficiency but did not require mechanical ventilation. Of 35 patients with severe AP, 34 had pancreatic necrosis and one patient with interstitial pancreatitis suffered from renal failure. Thirteen patients with pancreatic necrosis died during their hospital stay, resulting in an overall hospital mortality of $25.5 \%$. Of the patients who died, six (46\%) suffered from infected necroses, while in the survivor group only three patients $(15.8 \%)$ had bacterial infection. In severe AP, 19 patients suffered from cardiocirculatory failure ("shock"), 12 of whom were treated with intravenous catecholamines. Only two patients with pancreatic necrosis did not develop any systemic complications; 14 developed systemic complications but needed no intervention while 18 developed systemic complications requiring mechanical ventilation $(n=18)$, dialysis $(n=6)$, or surgical intervention $(n=10)$ (table 1).

METHODS

The cytokines IL-1 $\beta$, IL-6, IL-10, the antagonist IL-1RA, and the soluble IL-2 receptor (sIL-2R) were measured in serum at intervals using commercially available ELISA kits (DPC Biermann, Bad Nauheim, Germany and R\&D System, Oxford, UK) on a standard ELISA reader according to the manufacturer's instructions. IL- 8 was measured by a chemiluminescent immunoassay using the Immulite automated Luminometer (DPC Biermann, Bad Nauheim, Germany). The cytokines were chosen based on experience obtained in previous studies. As markers for pancreatic and monocyte/macrophage cytokine release, ${ }^{8-10}$ the proinflammatory IL-1 $\beta$ and its receptor antagonist IL-1RA were chosen. TNF- $\alpha$ was not measured as it is unstable, difficult to measure in the clinical setting, and is expressed in the pancreas in a similar manner as IL-1 $\beta .{ }^{11}$ As a marker of lymphocyte activation, we measured the soluble cleaved interleukin 2 receptor CD25, sIL-2R. IL-6 was determined as a lymphocyte activating cytokine and IL- 8 as a neutrophil activating chemokine. IL-10 was

Table 2 Peak values of routine chemical parameters in serum in mild and severe acute pancreatitis (AP) (mean (SEM))

\begin{tabular}{llllll}
\hline & Amylase (U/l) & Lipase (U/l) & LDH (U/l) & CRP $(\mu g / d l)$ & WBC $\left(\times 10^{5} / \mathrm{ml}\right)$ \\
\hline Severe AP & $1186(769)$ & $2230(543)$ & $616(126)$ & $321(51)$ & $23(12)$ \\
Mild AP & $1059(420)$ & $1844(832)$ & $243(61)$ & $160(45)$ & $18.4(4.2)$ \\
p Value & NS & NS & 0.01 & 0.005 & NS \\
\hline
\end{tabular}

$\mathrm{LDH}$, lactate dehydrogenase; CRP, C reactive protein; WBC, white blood cell count.

Table 3 Peak values of mediators in ascites and lesser sac (local) compared with peak serum values in severe acute pancreatitis (mean (SEM))

\begin{tabular}{llclcc}
\hline & $I L-1 R A(\mathrm{U} / \mathrm{ml})$ & $I L-1 \beta(p g / m l)$ & $s I L-2 R(p g / m l)$ & $I L-6(\mathrm{ng} / \mathrm{ml})$ & $I L-10(\mathrm{U} / \mathrm{ml})$ \\
\hline Local (n=24) & $3614.8(805)$ & $448.8(211)^{\star}$ & $1297(163)$ & $1339(149)^{\star}$ & $393(135)^{\star}$ \\
Serum (n=35) & $3616(407)$ & $4.88(1.05)^{\star}$ & $1440(205)$ & $666(101)^{\star}$ & $22.5(7.84)^{\star}$ \\
\hline
\end{tabular}

IL, interleukin; IL-1RA, interleukin $1 \beta$ receptor antagonist; sIL-2R, soluble interleukin 2 receptor.

^Significant difference. 

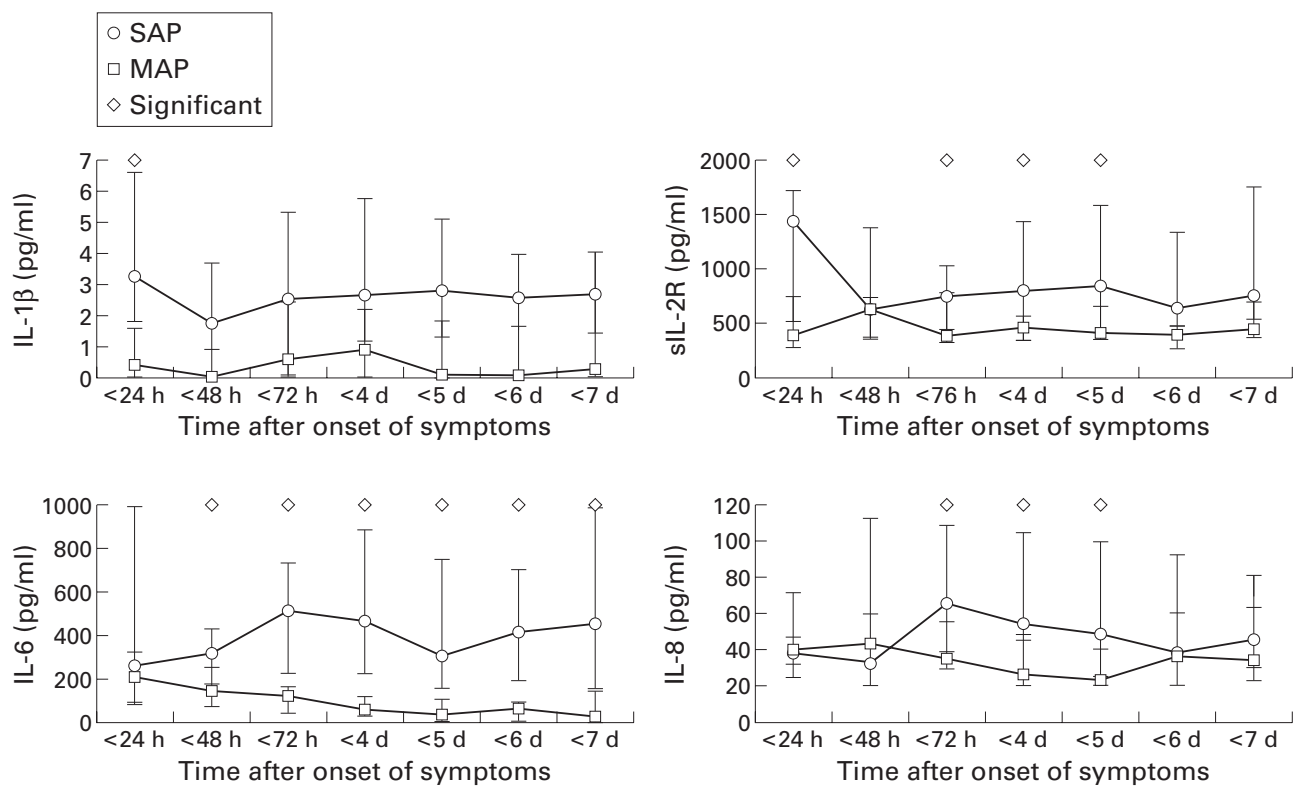

Figure 1 Time course of the proinflammatory mediators (interleukins (IL)-1 $\beta, I L-6$, and IL-8, and soluble interleukin 2 receptor (sIL-2R)) in serum in human acute pancreatitis. Values are median (interquartile range). SAP, severe acute pancreatitis; MAP, mild acute pancreatitis.

measured as a marker for Th2 lymphocyte activity. ${ }^{12}$

Routine laboratory parameters were determined in serum samples taken at the same time as samples for cytokine measurements (at the Department of Clinical Chemistry, University of Ulm, Germany). These parameters were serum concentrations of amylase, lipase, lactate dehydrogenase, $\mathrm{C}$ reactive protein (CRP), and total white blood cell count.

SAMPLE COLLECTION AND MEASUREMENTS

Blood samples were obtained on admission and at 24 hour intervals for the next six days of hospital treatment. Blood was collected as serum into EDTA tubes, immediately centrifuged at $3500 \mathrm{~g}$ for 10 minutes, aliquoted in $500 \mu \mathrm{l}$ portions, and stored at $-70^{\circ} \mathrm{C}$. Additionally, 24 ascites and nine lesser sac samples from 20 patients with SAP were obtained by fine needle aspiration or at laparotomy, centrifuged at $3500 \mathrm{~g}$ for 10 minutes, and stored at $-70^{\circ} \mathrm{C}$ for subsequent analysis.

STATISTICAL ANALYSIS

Statistical analysis was performed using the MedCalc statistical program (Schoonjans, Netherlands). All values are expressed as mean

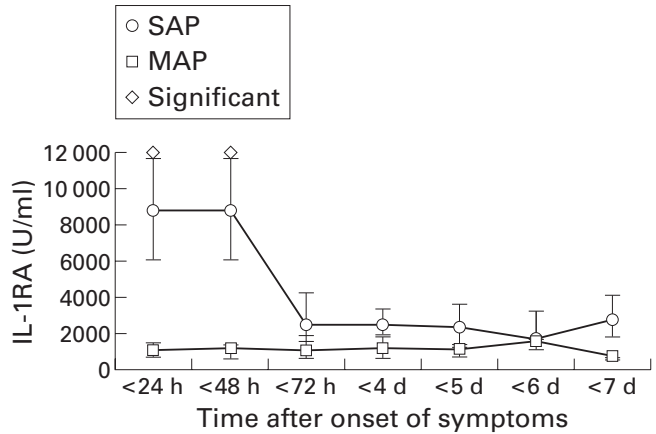

(95\% confidence intervals) and were compared using the Mann-Whitney U test. Correlation in multiple regression analysis was considered statistically significant when $p<0.05$. Cut off values, sensitivity, specificity, and positive $(+\mathrm{LR})$ and negative likelihood ratios (-LR) were determined by receiver operating characteristic analysis. A multiple regression analysis was performed comparing the independent variables pancreatic necrosis, sepsis, renal, cardiocirculatory and pulmonary failure, infected necrosis, and death.

\section{Results}

\section{ROUTINE PARAMETERS}

Table 2 shows the routine laboratory parameters in severe and mild AP. Amylase and lipase levels peaked on the first day but did not distinguish mild from severe attacks. CRP reached its highest value on day 3 and was significantly higher in SAP than in MAP (320 (102) v 160 (89) ng/ml; p<0.005). CRP and white blood count remained elevated throughout the observation period in SAP but not in MAP.

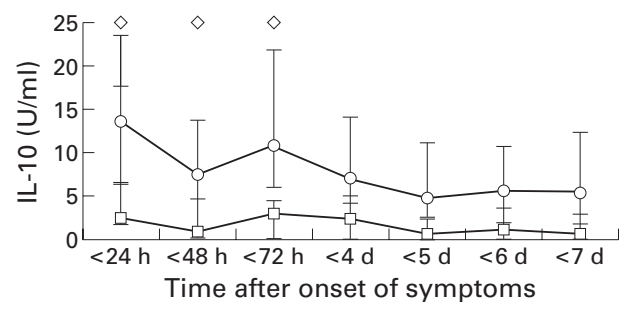

Figure 2 Time course of the anti-inflammatory mediators (interleukin 10 (IL-10) and interleukin $1 \beta$ receptor antagonist $(I L-1 R A))$ in serum in human acute pancreatitis. Values are median (interquartile range). SAP, severe acute pancreatitis; $M A P$, mild acute pancreatitis. 
Table 4 Peak serum concentrations of various mediators in severe versus mild acute pancreatitis (AP) (median (interquartile range))

\begin{tabular}{|c|c|c|c|c|c|c|}
\hline & $I L-1 \beta(p g / m l)$ & $I L-1 R A(U / m l)$ & $s I L-2 R(p g / m l)$ & $I L-6(n g / m l)$ & $I L-8(p g / m l)$ & $I L-10(\mathrm{U} / \mathrm{ml})$ \\
\hline Severe AP $(n=35)$ & $5.1(3.6-8.2)$ & $4759(3451-7000)$ & $996(574-2582)$ & $722(347-1680)$ & $100(73-158)$ & $13.6(11-55)$ \\
\hline Mild AP $(n=16)$ & $2.87(0.1-4.4)$ & $1796(1515-2425)$ & $568(373-819)$ & $268(107-443)$ & $110(59-678)$ & $2.8(0.2-4.9)$ \\
\hline $\mathrm{p}$ Value & 0.05 & 0.01 & 0.005 & 0.006 & NS & 0.01 \\
\hline
\end{tabular}

IL, interleukin; IL-1RA, interleukin $1 \beta$ receptor antagonist; sIL-2R, soluble interleukin 2 receptor.

Table 5 Peak serum concentrations of the mediators in survivors and non-survivors in acute pancreatitis (median (interquartile range))

\begin{tabular}{|c|c|c|c|c|c|c|}
\hline & $I L-1 \beta(p g / m l)$ & $I L-1 R A(U / m l)$ & $s I L-2 R(p g / m l)$ & $I L-6(n g / m l)$ & $I L-8(p g / m l)$ & $I L-10(\mathrm{U} / \mathrm{ml})$ \\
\hline Survivors & $3.3(1.1-5.8)$ & $3703(2421-6087)$ & $747.2(526-1071)$ & $427.6(237-1100)$ & $80.3(46.9-138)$ & $7.68(4.3-14.9)$ \\
\hline Non-survivors $(n=13)$ & $8.25(4.9-16.9)$ & $5412.5(3327-8260)$ & $2124.5(1066-3188)$ & $1670(983-1760)$ & $243.5(152-585)$ & $43.6(21.9-64.6)$ \\
\hline $\mathrm{p}$ Value & 0.002 & NS & 0.006 & 0.004 & 0.002 & 0.0005 \\
\hline
\end{tabular}

IL, interleukin; IL-1RA, interleukin $1 \beta$ receptor antagonist; sIL-2R, soluble interleukin 2 receptor.

Table 6 Peak serum values of mediators in various clinical complications in acute pancreatitis (median (interquartile range))

\begin{tabular}{|c|c|c|c|c|c|c|}
\hline & $I L-1 \beta(p g / m l)$ & $I L-1 R A(U / m l)$ & $s I L-2 R(p g / m l)$ & $I L-6(n g / m l)$ & $I L-8(p g / m l)$ & $I L-10(\mathrm{U} / \mathrm{ml})$ \\
\hline No sepsis $(n=40)$ & $2.93(0.5-5.7)$ & $2751(1717-6391)$ & $727.3(448-1077)$ & $427(223-1059$ & $114(54-706)$ & $6.7(3.1-12.9)$ \\
\hline Sepsis $(n=11)$ & $4.93(4.1-8.25)$ & $3825(3306-6585)$ & $1528.5(792-2224)$ & $867(524-1507)$ & $158(121-390)$ & $29.97(16.42-43.5)$ \\
\hline $\mathrm{p}$ Value & NS & NS & 0.04 & NS & NS & 0.02 \\
\hline No pulmonary dysfunction $(n=33)$ & $2.8(0.5-4.2)$ & $2751.5(1639-4176)$ & $581.4(428-776)$ & $295(219-429)$ & $88.2(41-1086)$ & $4.78(3.1-9.8)$ \\
\hline Pulmonary failure $(n=18)$ & $7.0(5.1-17)$ & $5495.5(3265-8260)$ & $2224(960-3205)$ & $1760(989-2071)$ & $157(95-337)$ & $31.4(17.6-61.4)$ \\
\hline $\mathrm{p}$ Value & 0.004 & NS & 0.001 & 0.0005 & NS & 0.0006 \\
\hline No renal dysfunction $(\mathrm{n}=37)$ & $3.47(2-5.1)$ & $3703(2451-5453)$ & $700(504-971)$ & $392(232-693)$ & $86.2(65-164)$ & $8.8(4.4-16.8)$ \\
\hline Renal failure $(n=14)$ & $7.1(5.9-10.4)$ & 8869 (3929-14508) & $3259(2620-4261)$ & $1670(1505-1780)$ & $155(152-158)$ & $67.5(40.2-97.4)$ \\
\hline $\mathrm{p}$ Value & 0.03 & 0.03 & 0.001 & 0.003 & NS & 0.008 \\
\hline
\end{tabular}

IL, interleukin; IL-1RA, interleukin $1 \beta$ receptor antagonist; sIL-2R, soluble interleukin 2 receptor.

LOCAL CONCENTRATIONS

Table 3 shows cytokine concentrations measured in ascites or lesser sac aspirates compared with peak concentrations in serum. Local concentrations of the three cytokines IL-1 $\beta$, IL-6, and IL-10 were significantly higher than those in serum. There was no significant difference between local and systemic values for IL-1RA and sIL-2R.

\section{SERUM CONCENTRATIONS}

Time course

As shown in fig 1 , both IL- $1 \beta$ and sIL-2R showed peak serum concentrations on day 1 after the onset of symptoms with significantly higher values in severe than in mild attacks. Both mediators remained increased throughout the observations period in severe AP. In common with IL-8, IL-6 reached its highest serum concentration on day 3 after the onset of symptoms. Significantly higher values in severe AP were found at most times during the observation period.

Figure 2 shows the time course of the two anti-inflammatory mediators IL-1RA and IL-10. In severe AP, IL-1RA was highest on the first two days but was not significantly increased in mild AP. In contrast, IL-10 was increased throughout the observation period in severe AP and was higher than in mild AP on the first three days after the onset of symptoms.

\section{Peak levels and complications}

Peak concentrations of cytokines in serum are shown in table 4. Peak concentrations of all mediators were significantly higher in severe compared with mild AP with the exception of IL-8 which did differ significantly in mild and severe attacks. However, peak serum IL-8 levels were significantly higher in lethal AP compared with survivors. Table 5 shows a similar pattern for IL-1 $\beta$, sIL-2R, IL-6, and
IL-10. For IL-1RA, the higher peak serum concentrations in non-survivors compared with survivors was not significant.

Peak serum concentrations in the presence or absence of sepsis, or pulmonary or renal failure are summarised in table 6. In AP complicated by sepsis, peak serum concentrations of sIL-2R and IL-10 were significantly increased while all other parameters did not differ significantly. In addition, only sIL-2R and IL-10 had significantly higher peak concentrations in all complications. In pulmonary failure, peak serum values of IL-1RA and IL-8 were not significantly elevated while IL- 8 was the only parameter that was not significantly increased in renal failure.

PREDICTIVE VALUE OF IL-6, sIL-2R, AND IL-1RA A maximum concentration of IL-6 of more then $450 \mathrm{ng} / \mathrm{ml}$ within the first seven days after the onset of symptoms indicated the development of pulmonary failure requiring treatment, with a sensitivity of $87 \%$, specificity of $88 \%$, $+\mathrm{LR}$ of 7.37 , and -LR of 0.15 . Peak sIL-2R concentrations of more than $1057 \mathrm{pg} / \mathrm{ml}$ within the first seven days after the onset of symptoms was a similarly useful parameter for prediction of a lethal outcome in AP with a sensitivity of $80 \%$ and a specificity of $77 \%$; +LR was 3.7 and -LR, 0.23. Within 48 hours after the onset of symptoms, a serum concentration of IL-1RA of more then $1850 \mathrm{U} / \mathrm{ml}$ distinguished between severe and mild attacks with a sensitivity of $82 \%$, specificity of $86 \%,+\mathrm{LR} 5.7$, and $-\mathrm{LR}$ 0.21 .

\section{Discussion}

In the clinical setting, early diagnosis and, if possible, assessment of the prognosis of AP is of major interest for the clinician. In previous clinical studies, pancreatic enzyme release was found to be a good diagnostic parameter in AP. 
But while amylase and lipase are generally accepted as diagnostic for AP, they are not prognostic of its severity. ${ }^{13}$ CRP has been established as a prognostic variable in human AP. ${ }^{14}$ In our prospective clinical study, we confirmed both the diagnostic value of serum amylase/lipase and the prognostic value of peak serum CRP. However, serum concentrations of CRP reached their peak only three days after the onset of symptoms, which considerably diminishes its clinical usefulness in early AP. In this respect, peak serum concentrations of IL- 6 was a much earlier prognostic parameter in assessing the severity of AP. Previous studies have established the role of IL-6 as an early marker of severity. ${ }^{15-20}$ In the clinical setting, IL-6 increases earlier and is a more sensitive marker of severity than CRP. ${ }^{20}$ Within the first 24 hours after disease onset, IL-6 is superior to $\beta_{2}$ microglobulin and comparable with IL-8. ${ }^{21}$ Our findings support the combination of IL- 6 with lipase, as recently suggested for the diagnosis and prognosis of AP in the clinical setting. ${ }^{22}$

IL-8, a neutrophil activating chemokine, has been found to correlate with disease severity in human $\mathrm{AP}^{23}{ }^{24}$ In determining the severity of $\mathrm{AP}$, systemic complications have been found to be associated with a significant increase in monocytic secretion of TNF- $\alpha$, IL- 6 , and IL-8 in patients with complicated AP. ${ }^{25}$ The same has been found for the release of IL-6, IL-8, and TNF- $\alpha$ by peripheral blood mononuclear cells in patients with severe $\mathrm{AP}^{26}$ In a clinical study, the role of serum IL-8 in predicting lethal AP was confirmed in another study by our group. ${ }^{24}$ In our study, peak concentrations of serum IL-8 were increased in lethal AP but peak values within the first seven days after the onset of symptoms were not significantly different in severe or complicated AP.

The release of the cytokines IL- $1 \beta$ and IL- 6 from inflamed pancreatic tissue has been linked to the development of distant organ dysfunction. ${ }^{11}$ Furthermore, increased pancreatic expression of IL- $1 \beta$ was seen in experimental $\mathrm{AP}^{8}{ }^{10}$ and inactivation of the IL-1 converting enzyme ICE has been found to result in milder pancreatitis and improved survival in experimental pancreatitis. ${ }^{27}$ Supporting these observations, we found that IL- $1 \beta$ was about 100 -fold increased locally compared with peak systemic concentrations and local concentrations of IL- 6 were twice as high as peak serum concentrations in severe AP. Peak serum concentrations of IL- $1 \beta$ and IL- 6 were significantly elevated in severe and lethal AP as well as in cases complicated by pulmonary and renal failure. In view of the aforementioned experimental studies, our study provides further support for local proinflammatory cytokine release in the development of distant organ complications.

As there is negative feedback between IL-1 $\beta$ and IL-1RA, ${ }^{3}$ the $\mathrm{IL}-1$ receptor antagonist (IL-1RA) may attenuate the severity of AP. Reduced pulmonary injury in rodent necrotising pancreatitis treated with IL-1RA ${ }^{28}$ and a beneficial effect of IL-1RA on survival and necrosis in experimental $\mathrm{AP}^{29}$ have been described. Increased serum IL-1RA has been found in human $\mathrm{AP}$, and in pancreatitis and sepsis, increased IL-1RA was associated with severity and multiorgan dysfunction. ${ }^{30} \mathrm{~A}$ lower IL-1 $\beta /$ IL-1RA ratio was found in AP complicated by sepsis and infected necrosis ${ }^{17}$ which gave rise to the notion that an imbalance in IL-1 $\beta / \mathrm{IL}-1 \mathrm{RA}$ is involved in the pathogenesis of complicated AP. In our study in human AP, IL-1RA distinguished between mild and severe attacks during the first 48 hours after the onset of symptoms with high sensitivity and specificity. Furthermore, we found that, contrary to IL-1 $\beta$, local IL-1RA concentrations in severe AP were not higher than peak serum values. While peak serum concentrations of IL- $1 \beta$ were significantly increased in AP complicated by pulmonary failure and during lethal courses of the disease, the receptor antagonist IL-1RA was not significantly elevated. The relationship between local and systemic concentrations of IL-1 $\beta$ and IL-1RA in complications in human AP may help to substantiate the concept of a pro- and anti-inflammatory imbalance in severe AP.

A pathophysiological role for IL-6 in the acute phase response comes from the broad proinflammatory action on various other cells and induction of hepatic production of acute phase proteins. ${ }^{31}{ }^{32}$ In experimental AP, IL-6 has been shown to be associated with distant organ complications ${ }^{33}$ and increased IL-6 has been linked to adult respiratory distress syndrome. $^{34}$ In isolated peripheral blood monocytes, increased IL-6 release was associated with systemic complications. ${ }^{25}{ }^{26}$ Similarly, in our study in human AP, IL-6 was a sensitive and specific marker of development of pulmonary failure and peak serum concentrations were increased in severe and lethal AP as well as in pulmonary and renal failure.

The anti-inflammatory cytokine IL-10 is a marker of Th2 lymphocyte activity. ${ }^{12}$ Before studies on IL-10 in human AP were conduced, a number of experimental studies on the potential of IL-10 in reducing necrosis and mortality in AP were published. ${ }^{45}{ }^{36}$ Underlining the potential anti-inflammatory effect, lower concentrations of serum IL-10 were described in mild early AP in humans. ${ }^{37}$ However, serum levels of IL-10 in severe AP were found to be increased in a recent study. ${ }^{38}$ Two other studies in human AP also found higher IL-10 levels in severe pancreatitis, serum IL-10 remained elevated for longer than in mild pancreatitis, and were positively correlated with increased IL- 6 and mortality ${ }^{15}$ In our study we confirmed the view of IL-10 as an early marker of severity; serum IL-10 levels were increased in severe and lethal pancreatitis as well as in sepsis, and pulmonary and renal failure. Together with the soluble IL-2 receptor (sIL-2R), serum IL-10 was the only parameter that was significantly increased in sepsis. This may be indicative of the role of $\mathrm{T}$ lymphocyte activation in the host defence against bacteria.

An increase in serum levels of sIL-2R and sCD8 combined with a decrease in serum sCD4 in AP compared with healthy individuals suggests early lymphocyte activation in $\mathrm{AP}^{39}$ 
Reduced circulating levels of CD4 positive lymphocytes in AP, which correlated with increased endotoxin and IL-6, confirm this observation. ${ }^{40}$ An imbalance of the macrophage-lymphocyte system with inadequately high lymphocyte activation in severe AP (reflected by increased levels of interferon $\gamma$ which is cosecreted with IL- 2 by Th1 cells) has been suggested previously. ${ }^{41}$ Increased levels of sIL-2R in severe AP have been found in human pancreatitis $^{39}$ and increased expression of IL-2 receptor on lymphocytes as a marker of systemic lymphocyte activation in severe AP has been reported. ${ }^{42}$ In our clinical study, we confirmed the important role of sIL-2R as a marker for severe $\mathrm{AP}$, especially in $\mathrm{AP}$ complicated by pulmonary or renal failure, or sepsis and during lethal courses of the disease. In fact, peak serum sIL-2R levels within the first seven days of the disease was a sensitive predictor of lethal outcome.

In experimental $\mathrm{AP}$, systemic lymphocyte activation has been linked to the development of distant organ complications. The development of pancreatitis associated distant organ failure, particularly pulmonary failure, has been found to be reduced in the absence of functional lymphocytes. ${ }^{43}$ Depletion of circulating $\mathrm{CD}^{+}$ lymphocytes or prevention of IL-2 mediated activation in experimental AP has been found to reduce systemic complications. ${ }^{44}$ In our clinical study, we identified the specific role of the proinflammatory cytokine IL-6, the lymphocyte activation marker sIL-2R, and the TH2 cytokine IL-10 in AP with complications. While this does not represent definite proof, together with a large body of evidence from experimental studies it allows interesting interpretations on the role of systemic lymphocyte activation in human AP. However, as no further conclusions can be drawn from this present study, more studies are needed to identify which lymphocyte subsets are involved and their time course of activation. Definitive knowledge of the immunological phenomenon may lead to the development of immunomodulatory treatments in severe AP.

The authors thank Susanne Kolodziej, Martin Grewe, Ulrich Beurer, Angela Härtner, and Erika Schmid for technical assistance and help in performing the statistics. This study was sponsored in part by a grant from the interdisciplinary centre for clinical research IZKF at the University of Ulm.

Conflict of interest statement. T Simon, M Hoover, $\mathrm{H}$ Quan and J Bolognese are employees of Merck \& Co Inc and potentially own stock and/or hold stock options in the company.

1 Norman J. The role of cytokines in the pathogenesis of acute pancreatitis. Am f Surg 1998;175:76-83.

2 Norman JG, Franz MG, Fink GS, et al. Decreased mortality of severe acute pancreatitis after proximal cytokine blockade. Ann Surg 1995;221:625-34.

3 Norman JG, Fink GW, Sexton C, Carter G. Transgenic animals demonstrate a role for the IL-1 receptor in regulating IL-1beta gene expression at steady-state and during the systemic stress induced by acute pancreatitis. I Surg Res 1996;63:231-6.

4 Rongione AJ, Kusske AM, Kwan K, Ashley SW, Reber HA McFadden DW. Interleukin 10 reduces the severity of acute pancreatitis in rats. Gastroenterology 1997;112:960-7.

5 Kusske AM, Rongione AJ, Ashley SW, McFadden DW, Reber HA. Interleukin-10 prevents death in lethal necrotizing pancreatitis in mice. Surgery 1996;120:284-8.

6 Bradley E. A clinically based classification system for acute pancreatitis: Summary of the international symposium on pancreatitis: Summary of the international sympo

7 ACCP/SCCM Consensus Conference Committee. American College of Chest Physicians/ Society of Critical Care Medicine Consensus Conference: Definitions for sepsis Medicine Consensus Conference: Definitions for sepsis
and organ failure and guidelines for the use of innovative therapies in sepsis. Crit Care Med 1992;20:864-74.
8 Fink GW, Norman J. Specific changes in the pancreatic expression of the interleukin 1 family of genes during experimental acute pancreatitis. Cytokine 1997;9:1023-7.
Denham W, Yang J, Fink G, et al. Gene targeting demonstrates additive detrimental effects of interleukin 1 and tumor necrosis factor during pancreatitis. Gastroenterology 1997;113:1741-6.

10 Fink GW, Norman J. Intrapancreatic interleukin 1beta gene expression by specific leukocyte populations during acute pancreatitis. F Surg Res 1996;63:369-73.

11 Norman J, Fink GW, Denham W, et al. Tissue-specific cytokine production during experimental acute pancreatitis. A probable mechanism for distant organ dysfunction. Dig Dis Sci 1997;42:1783-8.

12 Geissler K. Current status of clinical development of interleukin 10. Curr Opin Hematol 1996;3:203-8.

13 Heath DI, Cruickshank A, Gudgeon AM, Jehanli AM, Shenkin A, Imrie CW. The relationship between pancreatic enzyme release and activation and the acute phase protein response in patients with acute pancreatitis. Pancreas 1995; response in

14 Uhl W, Buechler M, Malfertheiner P, Martini M, Beger HG. PMN-elastase in comparison with CRP, antiproteases and $\mathrm{LDH}$ as indicators of necrosis in human acute pancreatitis. Pancreas 1991;6:253-9.

15 Berney T, Gasche Y, Robert J, et al. Serum profiles of interleukin- 6 , interleukin- 8 and interleukin- 10 in patients with severe and mild acute pancreatitis. Pancreas 1999;18: 371-7.

16 Brivet FG, Emilie D, Galanaud P. Pro- and antiinflammatory cytokines during acute pancreatitis: an early and sustained response although unpredictive of death. Parisian Study Group on acute pancreatitis. Crit Care Med 1999;27: 749-55.

17 Heresbach D, Letourneur JP, Bahon I, et al. Value of early blood Th-1 cytokine determination in predicting severity of acute pancreatitis. Scand f Gastroenterol 1998;33:554-60.

18 Inagaki T, Hoshino M, Hayakawa T, et al. Interleukin 6 is a useful marker for early prediction of the severity of acute pancreatitis. Pancreas 1997;14:1-8.

19 Formela LJ, Galloway SW, Kingsnorth AN. Inflammatory mediators in acute pancreatitis. Br F Surg 1995;82:6-13.

20 Viedma JA, Perez-Mateo M, Dominguez JE, Carballo F. Role of interleukin 6 in acute pancreatitis-Comparison with CRP and phospholipase A. Gut 1992;33:1264-7.

21 Pezzilli R, Billi P, Miniero R, et al. Serum interleukin-6, interleukin- 8 and beta2-microglobulin in early assessment of severity of acute pancreatitis-Cor

22 Pezzilli R, Morselli-Labate AM, Miniero R, Barakat B, Fiocchi M, Cappelletti O. Simultaneous serum assays of lipase and interleukin 6 for early diagnosis and prognosis of acute pancreatitis. Clin Chem 1999;45:1762-7.

23 Gross V, Andreesen R, Leser HG, et al. Interleukin 8 and neutrophil activation in acute pancreatitis. Eur $\mathcal{F}$ Clin Invest 1992;22:200-3.

24 Rau B, Steinbach G, Gansauge F, Mayer J, Grunert A, Beger HG. The potential role of procalcitonin and interleukin 8 in the prediction of infected necrosis in acute pancreatitis. Gut 1997;41:832-40.

25 McKay CJ, Gallagher G, Brooks B, Imrie CW, Baxter JN. Increased monocyte cytokine production in association with systemic complications in acute pancreatitis. Br F Surg 1996;83:919-23.

26 De Beaux AC, Ross J, Maingay JP, Fearon KCH, Carter DC. Proinflammatory cytokine release by peripheral blood mononuclear cells from patients with acute pancreatitis. $\mathrm{Br}$ f Surg 1996;83:1071-5.

27 Norman J, Yang J, Fink G, et al. Severity and mortality of experimental pancreatitis are dependent on interleukin-1 converting enzyme (ICE). $\mathcal{f}$ Interferon Cytokine Res 1997;17:113-18.

28 Tanaka K, Murata A, Uda K, et al. Interleukin 1 receptor antagonist modifies the changes in vital organs induced by acute necrotizing pancreatitis in a rat experimental model. Crit Care Med 1995;23:901-8.

29 Norman J, Franz M, Messina J, et al. Interleukin-1 receptor antagonist decreases severity of experimental acute pancreatitis. Surgery 1995; 117:648-55.

30 Hynninen $\mathrm{M}$, Valtonen $\mathrm{M}$, Markkanen $\mathrm{H}$, et al. Interleukin-1 receptor antagonist and E- selectin concentrations: A comparison in patients with severe acute pancreatitis and severe sepsis. $\mathcal{F}$ Crit Care 1999;14:63-8.

31 Tompkins RG. The role of proinflammatory cytokines in inflammatory and metabolic responses. Ann Surg 1997; 225:243-5.

32 Kingsnorth AN. Role of cytokines and their inhibitors in acute pancreatitis. Gut 1997;40:1-4.

33 Farkas G, Marton J, Nagy Z, et al. Experimental acute pancreatitis results in increased blood-brain barrier permeability in the rat: A potential role for tumor necrosis factor and interleukin 6. Neurosci Lett 1998;242:147-50.

34 Donnelly SC, Strieter R, Kunkel ST, et al. Interleukin 6 and development of adult respiratory distress syndrome in at-risk groups. Lancet 1993;341:643-7.

35 Van Laethem JL, Marchant A, Delvaux A, et al. Interleukin 10 prevents necrosis in murine experimental acute pancreatitis. Gastroenterology 1995;108:1917-22.

36 Denham W, Denham D, Yang J, et al. Transient human gene therapy: A novel cytokine regulatory strategy for experimental pancreatitis. Ann Surg 1998;227:812-20.

37 Pezzilli R, Billi P, Miniero R, Barakat B. Serum interleukin 10 in human acute pancreatitis. Dig Dis Sci 1997;42:1469 72 . 
38 Chen CC, Wang SS, Lu RH, Chang FY, Lee SD. Serum interleukin 10 and interleukin 11 in patients with acute pancreatitis. Gut 1999;45:895-9.

39 Pezzilli R, Billi P, Beltrandi E, et al. Behavior of serum soluble interleukin 2 receptor, soluble CD8 and soluble CD4 in the early phases of acute pancreatitis. Digestion 1994;55 268-73.

40 Curley P, McMahon RF, Lancaster F, et al. Reduction in circulating levels of CD4-positive lymphocytes in acute pancreatitis: Relationship to endotoxin, interleukin 6 and disease severity. Br F Surg 1993;80:1312-15.
41 Chaloner C, Laing I, Heath DI, Imrie C, Braganza JM. Dysregulation of $\mathrm{T}$ cell-macrophage network in severe acute pancreatitis. Biochem Soc Transact 1993;21:451.

42 Widdison AL, Cunningham S. Immune function early in acute pancreatitis. Br F Surg 1996;83:633-6.

43 Mayer J, Laine VJO, Rau B, et al. Systemic lymphocyte activation modulates the severity of diet-induced acute pancreatitis in mice. Pancreas 1999;19:62-8.

44 Mayer J, Laine VJO, Gezgin A, et al. Single shot FK506 and OKT3 reduces early severity in experimental acute pancreatitis. Eur F Surg 2000;166: 